Précis of

\title{
Excellent Beauty: The naturalness of religion and the unnaturalness of the world.
}

(published by Columbia University Press, 2015.)

Eric Dietrich

Philosophy Dept., Binghamton University, Binghamton, New York.

President John Kennedy once said: “... the great enemy of the truth is very often not the lie-deliberate, contrived, and dishonest—but the myth-persistent, persuasive, and unrealistic." President Kennedy was, of course, concerned with political myths. But a far deeper myth pervades our land these days: It is the myth of an unstoppable and universally reducing science. This myth of course has political ramifications, as we will see. The myth of unstoppable science sadly continues the Pre-Copernican tradition: we are at the center of the universe (it helps to say this while pounding one's chest). In Excellent Beauty, I expose this myth for what it is, and show you a world that is beautiful, austere, and mysterious --- and which lacks a human center completely.

There are those who already reject this myth about science. Unfortunately, they are a part of a worse problem, a dark and dangerous problem confronting our nation. These are the science denialists. The US is a country where fully one half of its citizens deny the theory of evolution, either in whole or in part - and that's just 
for starters. These citizens do deny that science is unstoppable and universally reducing. But they assert that the boundaries of science are constituted by their religion. And their religion places them at the center of their universe. As we all know, this group contains people who deny that planet Earth is heating up. But it also contains people who are glad the Earth is heating up because this means that the second coming is at hand. Obviously addressing the problem of global warming under such conditions is difficult.

But the real problem with the science denialists is that they make it seem as if the only choice is between no science at all and an unstoppable and universally reducing science. But these are not the only choices.

First, though, here is an example of the power of science. In a shocking - but denied - triumph, biological science can now explain why humans are religious: religion is an evolutionary adaptation. Consider two facts: (Fact 1) Religions on Earth today number in the hundreds of thousands, if you count variations. And there are dozens of major religions - religions with at least half a million adherents. (Fact 2) Religious people are immune to almost any data that is incompatible with their religion. Religious beliefs often exist unperturbed by the onslaught of science. What could explain these two facts? Only one thing: Evolution. The propensity for religion is a part of the genetic blue print of humans. Early archaic humans who were religious out-competed those who were not. How? Religion apparently is first and foremost a group bonding mechanism. It also piggybacks on a wide variety of 
psychological mechanisms that implement "magical thinking", to which we are all susceptible. So, religions create groups, and, since groups are in our case the major unit of selection for evolution, such groups flourished.

So, our fellow Americans who deny evolution, deny it because evolution made them evolution-deniers. Religion is thus sidelined, though, of course, it will never go away.

How is it that many Americans and almost all scientists accept evolution, then? An excellent question ... for another day.

Now for the promised mysteries. There are many religious mysteries, e.g., the Christian transubstantiation whereby bread and wine literally become the body and blood of Christ. All of these mysteries require belonging to the relevant religion. And none of these mysteries are real. However, our universe is crawling with real mysteries, free and available to everyone, with no membership or sacrifice required. These mysteries are what I call the Excellent Beauties. And they are all unearthed by science. (I take the term “Excellent Beauty” from Francis Bacon's famous quote "There is no Excellent Beauty that hath not some strangeness in the proportion." "Of Beauty")

Let's get right to the examples. Probably the most important Excellent Beauty is consciousness. I don't mean anything strange or unusual by the term 
"consciousness." Conscious is from one perspective, the most ordinary thing in the universe. It is one's experience of colors, of smells, sounds, tastes, feelings, touches and textures, etc. It goes away during part of our sleep and during serious surgeries. After decades of robust effort, science cannot explain consciousness. In fact, we don't even know what a theory of consciousness would look like - shown the correct theory by space aliens, we couldn't even begin to tell if it was correct or not. Neuroscience is completely useless when it comes to consciousness. Neuroscience cannot explain why aspirin works. The situation is so dire that some scientists and scholars take seriously the idea that consciousness is not a physical property of our universe. It is instead something nonphysical and probably fundamental to the universe, like gravity or energy or mass - though of course these latter three are physical. The idea that consciousness is fundamental is taken very seriously. Within this idea, it is assumed that consciousness, as some nonphysical property of the universe, showed up when everything else did - at the Big Bang. If this hypothesis is correct, then it may well be that almost everything is conscious: all animals, certainly, but also all plants, all molecules, all atoms, and, going the other way, perhaps all planets, suns, galaxies, and other cosmological phenomena. This view that everything is conscious is called panpsychism, and like I said, it is taken very seriously by some.

A second Excellent Beauty is the brute rarity of what you call the common place. You are made of matter and energy and use matter and energy every second of every day. As far as you are concerned, matter and energy are everywhere and 
make up the universe. Recent measurements and theory, however, show that matter and energy comprise only about $4 \%$ of the universe. Most the universe is made up of we know not what. We call this unknown stuff "dark matter" and "dark energy," but those are just labels deployed because cosmologists had to use something for tax purposes. Moving on, consider the numbers you use everyday: the counting numbers, fractions, negative numbers. It is provable in math that all these numbers together amount to nothing on the real number line, the infinite line we learned about in algebra, stretching to positive and negative infinity. This real line is in fact made up of numbers that are quite strange and which you almost never use, and when you do use them, you use at most 1 or 2 or them: $\pi$ and $e$. The numbers we use everyday are all but nonexistent - they are essentially "drowned out" by the strange numbers we never use and mostly are ignorant of.

Did you know that infinity comes in sizes? That's right, some infinities are bigger than others. How can one infinity be bigger than another infinity if both are infinitely big? No one knows, but that this is in fact true is easily proved. For example, the infinity of strange numbers, like $\pi$ and $e$, that we never use is provably bigger than the infinity of the counting numbers, $1,2,3,4,5, \ldots$ Not only are some infinities bigger than others, but some collections of numbers which are clearly not the same size are nevertheless provably exactly the same size. Example: there are an infinite number of counting numbers: $1,2,3,4,5 \ldots$ Now consider a subset of the counting numbers -- the even numbers: $2,4,6,8,10 \ldots$ The counting numbers contain not only all the even numbers, but also all the odd numbers. So the set of 
counting numbers is clearly bigger than the set of even numbers. Yet it is easily demonstrated that the collection of even numbers is exactly the same size as the collection of counting numbers. Infinity, then, is our third Excellent Beauty.

A fourth. How many people do we need to gather together in a room to be 100 percent sure that two of them will have the same birthday? 366 . Right ... ok, good. How many people do we need to gather together in a room to have a 50 percent chance that two of them will have the same birthday? That's right, 23 (!). Not 183, which is one-half of 366.

Did you know that there is a very old, currently undecipherable text complete with detailed colored drawings sitting in Yale University's Beinecke Rare Book and Manuscript Library? The author, purpose, and meaning of the text are unknown. Attempts to decode it or translate it defy all modern techniques used by linguists and cryptologists. It's called the Voynich Manuscript. Most scholars believe it was written sometime in the fifteenth or sixteenth century, but no one is sure, though recent carbon-14 dating does put the date of the paper in the early fifteenth century. The language the manuscript is written in, if indeed it is a language, is completely baffling. Detailed statistical analysis of the symbols making up the manuscript, however, leads most scholars to believe that it is in fact written in some language, just not one used on planet Earth by any known culture or people. 
And for our final Excellent Beauty: there are true contradictions in our world. These are statements that have to be false, but are also true. There are also events that cannot occur, but do. It is reasonable to call these true contradictions paradoxes. So another way to put this point is to say there are real paradoxes in our world. It is shocking how common some of these are. The most common of these paradoxes is motion itself, which, and I know this sounds unbelievable, we still don't understand well.

Please note that I have not discussed any Excellent Beauties from quantum mechanics. Quantum mechanics is famous for weird and strange things, so I thought I would skip them here.

We have barely scratched the surface. The existence of these Excellent Beauties is the true boundary science. There is a nonmundane world behind our mundane one. There is a world of shocking, real, and beautiful mysteries lying just over the horizon of our ordinary lives.

What does the existence of the Excellent Beauties mean? I don't know. However, I personally think that they should instill in us several ideals:

A friendlier acceptance of uncertainty, A lighter grasp on all our knowledge, An ongoing openness to change, 
A willingness to instigate change,

An active search for the failure of all generalities (including the ones made here),

A willingness to question everything (even this statement),

And finally, less epistemic arrogance.

It certainly does seem as if science has shown us a world of magnificent richness and depth, a world that is essentially open-ended, a world that is, at root, mysterious. Perhaps it wouldn't be out of place to approach our mysterious world with a kind of reverence, celebrating the Excellent Beauties for what they reveal: a strange universe of which we are intimately a part, but which does not revolve around us. 